\section{ON BACKACHE AS A SYMPTOM OF RECTAL DISORDER. ${ }^{1}$}

BY E. HARDING FREELAND, F.R.C.S. ENG.,

SURGEON TO THE ST. GEORGE'S AND ST. JAMES'S DISPENSART, LONDON.

WHen my friend Mr. Alfred Kirby honoured me with an invitation to read a paper before your society it occurred to me that it would be more profitable if $I$ were to address you on some topic of general interest rather than on some obscure disease or unique operation, the only possible interest in which would centre in the fact that it was a rarity. This, then, must be my excuse for venturing to introduce to your notice such a common-place ailment as backache with the hope, moreover, that $I$ may be able to show to some of you at any rate an old friend in a new guise, and possibly to excite fresh interest in a symptom, the constant reiteration of which must have become to many of you exceedingly wearisome.

The word "backache," when used in a general sense, would naturally include any and every ache or pain referred to the posterior surface of the trunk. But in medical parlance, I take it, this word has come to be used in a somewhat technical sense and to be restricted to pain occurring at or below the level of the loin. For my present purpose I propose to limit its meaning still further and to define it as any morbid sensation referred to that portion of the back which corresponds to the posterior surface of the sacrum. With this symptom you must all be perfectly familiar. Indeed, so common is it that in all probability hardly anyone here present completes his daily round without having heard it made the cause of complaint by one or other of his patients. And yet I have good reason to believe that the importance of this symptom is frequently underestimated and that its true significance is often overlooked. Were it not for the fact that this symptom gives rise to immeasurable distress its very commonness should render it worthy of our careful consideration and investigation, for it is superfluous on my part to remark that the more common the ailment the greater will be the number of sufferers seeking relief, and that in reality more good is attained by the relief of a score of people suffering from some trivial but troublesome complaint than by the relief of one suffering from some obscure yet serious disease.

In considering the cause of pain referred to any part of the body it is first of all necessary to consider the nervesupply of the part affected and then to ask oneself the question how a stimulus, directly or indirectly applied to the nerve terminals of the part, can act as a source of irritation and a cause of pain? Now it is quite clear that the stimulus which evokes response in the peripheral nerves of any part may be either centrali.e., having its origin in the brain or spinal cord-or peripheral. In the latter case the stimulus may be direct or indirect-i.e., it may be applied to the terminal fibrils of the nerves implicated or it may be transferred to these through neighbouring nerves by reflex action from a distance. For the present I do not propose to take into consideration either central or direct peripheral causes, but to confine my remarks to reflex causes; and in order the better to appreciate these I would ask you for a moment to allow me to refresh your memory with regard to the nervous anatomy of the parts under consideration.

According to Kocher and other well-known authorities on cutaneous nerve distribution the parts covering the back of the sacrum are supplied with sensibility by the terminal filaments of the posterior primary divisions of the fourth sacral nerves. You will doubtless remember that the anterior primary divisions of these nerves divide into two branches, the larger of which again splits up into branches which course forward through the pelvis towards the base of the bladder, mingling as they go with branches of the pelvic sympathetic plexus. Some of these pass upwards on the walls of the bladder; others pursue a similar course on the walls of the vagina, a few reaching the uterus; others, again, to which I wish especially to direct your attention, are distributed to the

1 A paper read before the New Cross Medical Society on March 7th, 1900. lower part of the rectum. Passing through the space between the two sphincters they break up into filaments, some of which pass downwards to be distributed to the skin of the anus, while others pass upwards to be distributed to the mucous membrane of the anal canal and rectal ampulle. Theoretically, then, one would expect to find backache frequently associated with derangement of the pelvic organs, and such indeed turns out to be practically the case.

In the minds of most of us there is no doubt a tendency to associate together backache and uterine disorder, and when a woman comes to us complaining of backache we instinctively think of the uterus as the organ most probably at fault. But, al though it is true that uterine derangement and backache are frequently associated we should always be on our guard against rashly assuming that their relation. ship is one of cause and effect. My own experience is that these two conditions are not nearly so frequently interdependent as is usually supposed. Indeed, my conviction on this point is so strong that whenever a case presents itself in which these two conditions co-exist I make it a rule, while admitting their possible inter-dependence, to be sceptical about this relationship. The same remarks apply with equal force to backache associated with functional derangement of the bladder. This brings me to the point which I wish especially to emphasise this evening-viz., that backache is frequently due to reflex irritation having its origin in the rectum, and that even when it is associated with symptoms referable to the other pelvic organs, the bladder or the uterus, the rectum will not infrequently be found to be the organ primarily at fault. The following brief résumé of an actual case well exemplifies the condition to which I particularly wish to direct your attention.

CASE 1.-A man, aged 39 years, came to me complaining of a dull aching pain at the bottom of the back (over the sacrum) which came on usually after his lunch and persisted for the rest of the day, materially interfering with his capacity for work. He presented features of a type which I shall presently endeavour to describe, and had for the past montb been sitting day by day, week in and week out, at his desk, attending to urgent and anxious business. He stated that his bowels were regular, for although of late there had been a tendency to constipation he had managed to keep his bowels acting daily by purgatives. On passing my finger into the rectum I found it empty except for a hard fæcal nodule which was just within reach of the finger tip anteriorly. This and two others, all of which bore evidence of prolonged residence within the bowel, were removed by an enema, and under the influence of a saline purge each morning coupled with two-grain doses of quinine twice daily the pain rapidly vanished.

Cases of this type I could multiply indefinitely; and no doubt many of you will have observed, in common with my. self, that backache is not infrequently a cause of complaint among men. In such cases of course the question of the uterus as a causative factor can at once be put out of court. In my experience, as I have just hinted, the man who comes complaining of backache usually conforms to a certain type, which it is important to recognise, for it is often the recognition of this type which is instrumental in directing attention to the true state of affairs. Usually endowed with considerable mental activity and conscientious of ten to the last degree, his mental capacity far outstrips his physical strength. He is capable, nevertheless, if put to it, of getting through a considerable amount of hard work and of enduring a considerable amount of mental overstrain. $\mathrm{He}$ is in a word wiry. But let such a one become overworked and overworried, let him, in other words, draw largely on his reserves of nervous energy, and he soon becomes nervous, irritable, morose, and generally out of sorts. This change in his condition is more noticeable to his friends than to himself. His digestion becomes deranged, but although he is cognisant of the fact he pays little heed thereto, for it is not his great trouble. His bowels, he will tell one, are regular, or, if not, that there is a tendency to constipation which he relieves perfectly by a judicious use of purgatives. If the stools be examined they will be found to contain scybalous masses with an admixture of gelatinous tenacious mucus of which in all probability he has no knowledge. But his chief cause of complaint, the ailment which worries him to the exclusion of all others and on which for the time being his whole mental energy is concentrated is a dull weary aching pain over the sacrum, sometimes continuous, sometimes intermittent, which prevents him concentrating his mind on 
his work at a time when it is important that he should give it his best and undivided attention. If the trouble be taken to analyse the group of symptoms which I have just endeavoured to portray it will be found that the only truly objective sign in the whole lot is the passage of scybalous stools and viscid mucus. This sign is the keystone of the whole situation, and to my mind it is of no doubtful significance-its presence points unmistakeably to chronic rectal catarrh. Having arrived so far, it is probably safe to conclude that the dyspeptic symptoms are due to catarrh of the stomach and that there exists, in fact, a chronic catarrhal condition of the whole gastro-intestinal tract. The next question which arises is, How is this catarrh brought about? I believe that it is mainly in the following way. Nervous depression causes diminution of functional activity generally, in which the cardio-vascular system shares, causing a tendency to general venous congestion, and especially in the great venous system connected with the liver-the portal vein and its tributaries. This, in turn, working backwards causes congestion of the whole gastrointestinal tract, and in process of time a catarrhal condition is set up with a tendency to the secretion of viscid tenacious mucus and the formation of hard scybalous freces. These masses, passed on from the colon, sometimes get lodged in one of the rectal folds or just within the rectal ampulla and there act as irritants to the nerve terminals which are distributed to the lower end of the rectum. This source of irritation often manifests itself by reflex action in the form of pain or some other morbid sensation referred to the posterior surface of the sacrum. The presence of these scybalous masses can easily be confirmed by anyone who will take the trouble to pass his finger into the rectum.

At one end of the line then there is worry, which may be considered the prime factor, and at the other end worry-on account of the pain-as the ultimate factor in the case. As intervening factors there is the chronic catarrh, which prevents the patient from absorbing and assimilating a sufficient amount of nutriment to recoup his already jaded nervous system, and the formation of scyoalous masses which, by the irritation which they cause, tend still further to jade the aiready wearied nerves. Thus a vicious circle is created which, unless the true condition of affairs is recognised, it is very difficult to break. Once the condition of affairs is diagnosed, however, the indications for treatment are selfevident. These obviously are: (1) to remove the scybalæ; (2) to secure an efficient and regular action of the bowels; (3) to relieve the catarrh; and (4) to improve the general health.

For the relief of the catarrh I know of no more satisfactory remedy than ichthyol in doses of from five to ten grains or more night and morning. It relieves the congestion, improves the appetite, and stimulates peristalsis. Quinine in two-grain doses will also in some cases be found beneficial. Theoretically, no doubt, bearing in mind the prime cause, a complete cessation from work and a change of scene and air would be indicated; but usually the necessity for sticking to business which was the prime factor in the case still exists, and it is very seldom that the patient can be induced to relinquish his calling. Even if he could be persuaded so to do, it is a great question whether the anxiety over business neglected would not be a greater evil than the mental strain caused by a moderate amount of business done. Practically, therefore, I think that it is wise to steer a middle course, advising the patient to curtail his hours of work, to spend as much time as possible in the open air, to indulge in a moderate amount of exercise, to partake of as much good plain food as he can digest, and, in short, to adopt regular habits of living generally.

Let it not be thought, however, that I wish to convey the idea that such cases occur exclusively among men; on the contrary, they occur with equal, if not greater, frequency among women who, allowing for differences in habits, mode of life, and environment, conform mainly to the same type. My only reason for laying special stress on the occurrence of such cases among men has been that I was anxious to eliminate all idea of the uterus as a causative factor. But the aspect of such cases is not always quite so simple, and the pain or discomfort is not always due to what may be termed functional causes, but in many cases may be traced to more or less serious organic disease-e.g., piles, ulcer, and cancer-as exemplified by the following cases.

CASE 2.-Some time ago I was consulted by a young married woman whose only cause of complaint was a severe aching pain at the bottom of the back which tormented her continuously. This pain she had borne patiently for many months until about two months previously to my first seeing her so bad had it become that, other remedies having failed, she had submitted to excision of the coccyx but without relief. On digital examination of the rectum a circular ulcer of about the size of a sixpenny-piece was felt just within the rectal ampulla posteriorly. To make a long story short, pari passu with the healing of the ulcer the pain diminished and finally disappeared.

In this case a simple investigation in the first instance would have revealed the true canse, would have saved the patient noonths of suffering, and would have prevented a needless operation.

CASE 3.-About two years ago I saw a woman, aged 55 years, who had unmistakeable signs of rectal cancer which was inoperable. A colotomy prolonged her life for some 18 months. This patient told me that for some six months before her symptoms definitely directed attention to the bowel her only cause of complaint was a continuous dull wearing pain at the bottom of the back.

This I believe to be quite a common occurrence in the early history of rectal cancer. The only symptom for some time is backache. What the ultimate result of this case would have been had it been diagnosed in its early stages it is, of course, impossible to say, but when we reflect on the brilliantly successful results of prompt surgical treatment in the early stages of rectal cancer and compare these with the hopelessly miserable condition of the patient when the disease has been allowed to drift on into the later and inoperable stages it is reasonable to suppose that things might have been different. The lesson $I$ think we should all learn from such cases is that when a patient comes to us complaining of backache we should not treat the symptom in a careless or perfunctory manner, putting it down to weakness, rheumatism, and so forth; that we should not rest content until every possible cause of the pain has been carefully investigated; and that no investigation should be considered complete until the state of the rectum has been ascertained.

So much then for cases of rectal disorder where backache is practically the only symptom and where we have little else to guide us to the true state of affairs. I should like now to refer very briefly to a class of case where backache is associated with other direct symptoms which, unless properly understood, are likely to prove very misleading. It is not uncommon to find patients complaining of backache complicated by bladder disorder, as evidenced by frequency of urination or retention of urine; or by (?) uterine derangement, as evidenced by vaginal discharge. These cases, unless he is warily on his guard, form veritable pitfalls to the practitioner, as the following cases bear witness.

CASE 4.-A man, aged 39 years, who was otherwise in the best of health, came to me complaining of a sense of weakness at the bottom of the back and irritability of the bladder of about three weeks' duration. He assured me that the bowels were acting regularly, yet under the influence of an efficient purge he passed a large watery stool containing several scybalous masses the colour and consistence of which betokened prolonged residence within the bowel. The highly satisfactory result of this method of treatment was effectually to relieve his symptoms.

CASE 5.-I was sent for in hot haste to see a woman, aged 45 years, who was suffering from inability to pass urine and who in consequence was in much distress. She told me that she had suffered more or less from difficult urination for about a month and had been treated for this disability but without success. She further told me that this symptom had been accompanied by backache. So far from suffering from constipation she informed me that recently there had been a tendency to diarrhcea. Thinking that the urinary retention might be caused by a retroverted uterus I made a vaginal examination, and to $\mathrm{my}$ surprise found that cavity rendered almost impenetrable by what turned out to be an accumulation of frecs in the rectum. The removal of this by copious injections of soap and water completely relieved the symptoms.

In either of the above cases it would have been very easy to have misinterpreted the true state of affairs and to have fallen into the trap of treating the bladder instead of the rectum, thus leaving the main cause untorched and the patient consequently unrelieved. This error, as I have incidentally remarked, actually occurred in one of the cases. It is always well, therefore, in endeavouring to unravel cases similar to those which I have just very briefly narrated, to 
bear in mind the fact that any source of irritation having its origin in the lower end of the rectum is liable to cause functional derangement of the bladder. If this fact be borne in mind the practitioner will seldom go astray.

Before concluding I should like to say a few words on that very common class of case where backache and leucorrhcea are associated together as prominent symptoms, a good example of which is the following.

CASE 6.-A young unmarried woman, aged 28 years, consulted me for backache associated with leucorrhœea of some six months' duration. On making a vaginal examination I noticed two external piles at the margin of the anus, and finding the uterus normal I forthwith directed $\mathrm{my}$ attention to the rectum, an examination of which revealed internal as well as external piles. When informed of the true state of affairs the patient vouchsafed the information that she had suffered from constipation and pain on defecation for some time past-a valuable piece of evidence which she evidently intended in the first instance to keep to herself. The upshot of the case was that the piles were removed with a speedy cessation of the symptoms.

In connexion with this case I would like to point out that in any case of leucorrhoea it is always well to bear in mind the fact that reflex irritation having its origin in the rectum may be, and often is, a determining factor and that the source of this irritation will frequently be found to be a crop of piles. I have repeatedly met with such cases and it is abundantly clear that no amount of tonics and astringent injections will cure them so long as the main cause remains untouched.

To sum up, the chief points which I have endeavoured to substantiate this evening are the following: (1) that backache is not only a common but also a very important symptom; (2) that whether it be practically the only symptom present or whether it be associated with other more or less definite symptoms it is well worthy of a careful and searching investigation; and (3) that no investigation should be considered complete until the condition of the rectum has been ascertained.

In conclusion, I have to thank you for your kind attention and to express the hope that I have not wearied you by what of necessity has been a somewhat fragmentary discourse. If so my excuse must be that when one has paid special attention to any particular subject one is apt to think that others also will take an equal interest therein.

Beaumont-street, $\mathrm{W}$.

\section{Clinital a dotes:}

MEDICAL, SURGICAL, OBSTETRICAL, AND THERAPEUTICAL.

\section{NOTE ON THE INFLUENOE OF THE TEMPERATURE} OF LIQUID AIR ON BACTERIA. ${ }^{1}$

By Allan Macfadyen, M.D. Edin., AND

\section{S. Rowlund, M.A.}

IN a previous communication to the Royal Society ${ }^{2}$ it was shown that no appreciable influence was exerted upon the vital properties of bacteria when exposed for 20 hours to the temperature of liquid air $\left(-183^{\circ} \mathrm{C}\right.$, to $-192^{\circ} \mathrm{C}$.). Further experiments have since been made in which the organisms were again exposed to the temperature of liquid air for a much longer period-viz., seven days.

The organisms employed were bacillus typhosus, bacillus coli communis, bacillus diphtheriæ, bacillus protens vulgaris, bacillus acidi lactici, bacillus anthracis (sporing culture), spirillum choleræ Asiaticæ, staphylococcus pyogenes aureus, bacillus phosphorescens, a sarcina, a saccharomyces, and unsterilised milk. Instead of being exposed as formerly on the actual media in which they were growing the organisms were submitted to the cooling process in the form of a broth emulsion in hermetically sealed fine quil

1 A paper read before the Royal Society on April 5th, 1900. Com municated by Lord Lister, P.R.S.

2 THE LANCET, March 24th, 1900, p. 849 tubing. This allows of complete immersion and effects a considerable economy in the amount of liquid air used, besides greatly facilitating manipulation. The liquid air was kindly furnished by Professor Dewar and the experiment was conducted in his laboratory. In the course of the experiment the loss by evaporation of the liquid air was made up by adding fresh portions from time to time. In this way the temperature of about $-190^{\circ} \mathrm{C}$. was maintained uninterruptedly through the whole period of the experiment. At the same time considerable care had to be taken in conducting the first cooling in order to avoid fracture of the quil tubes. A preliminary cooling was therefore effected by means of solid $\mathrm{CO}_{2}$. After the expiration of a week the tubes were removed with cork-tipped forceps and placed in a strong glass vessel till thawing was complete. The tubes were then opened and the contents transferred to suitable culture media. In each case a direct microscopical examination was made to detect any possible structural changes.

It is a remarkable fact that, notwithstanding the enormous mechanical strain to which the organisms must have been exposed, a strain far exceeding in amount any capable of being produced hitherto by direct mechanical means, not the slightest structural alteration could be detected. The subcultures made at the conclusion of the experiment grew well and in no instance could any impairment in the vitality of the organisms be detected. In one or two instances only growth was slightly delayed, an effect which might bave been due to other causes. The photogenic bacteria grew and emitted light, and the samples of milk became curdled.

The above experiments show that bacteria can be cooled down to $-190^{\circ} \mathrm{C}$. for a period of seven days without any appreciable impairment of their vitality. It has not yet been possible to undertake the experiments with liquid hydrogen.

\section{A NEW METHOD OF TREATING FEMORAL FRACTURES IN THE INFANT.}

\section{By JoHN D. RICE, M.B., B.CH. R.U.I.}

ON August 24th, 1899, I saw a newly-born infant with a fracture in the upper third of the right femur, all the classical symptoms being present. As the mother did not intend to nurse the child-and under the circumstances this would have been well-nigh impossible - I had the child removed to the Eltham Cottage Hospital, where I proceeded to deal with the injury. For several days I persisted with the ordinary methods for placing the fragments at rest, but found none of them gave the desired result. It then occurred to me that if a child could live in utero with its thighs flexed on the abdomen it might equally well do so ex utero; accordingly $I$ flexed the injured limb on the abdomen, turning the foot over the shoulder of the same side (having previously placed boric acid and wool between the opposed surfaces). I then bandaged the limb with a washed flannelette bandage firmly to the abdomen and thorax, extension being kept on the foot. I raised the head of the cot six inches, and carried, as counter-extension, a loop of soft bandage round the ankle and fastened the end to the rail of the cot; a sandbas wrapped in flannel placed on each side of the child prevented lateral motion. The progress of the case was uneventful. The child ceased crying, fed and slept well, and was discharged in three weeks with perfect movement in the limb and no shortening, nor is there any now (April 6th).

In a child a little older it might be advisable to aid the body-weight extension by using a small weight attached to the sides of the buttocks by a large loop of adhesive plastez and a stirrup sufficiently large to avoid being soiled by the evacuations.

New Eltham, S.E.

\section{DISLOCATION OF THE EPIPHYSIS OF A METACARPAL BONE.}

By E. KeN HerRING, M.R.C.S. ENG., L.R.C.P. Loyd., HONORARY SURGEON, MOOROOPUA HOSPITAL; LATE SHNIOR RESIDEXT SURGEON, BALLARAT DISTRICT HOSPITAI.

THE skiagram which I send with this, showing the extremely rare condition of dislocation of the epiphysis of a 